\title{
Stellenregister
}

A.

- Fr. 36-42 Radt: 94 Anm. 98

-Pr. 83: 56 Anm. 62

Ach. Tat.

- 1,4: 162 Anm. 59

$-1,4,2-5: 136$

-1,4,3: 51, 129 Anm. 78, 136

- 1,6,5: 136 Anm. 109

-1,12: 137, 139

$-1,12,5: 139$

$-1,13: 137,139$

$-1,13,2: 139$

$-1,13,4-6: 139$

$-1,14: 137$

- 1,14,2f.: 139

- 1,15,2: 135 Anm. 105

- 1,15,3 f.: 135 Anm. 105

- 1,15,4: 136 Anm. 105

- 1,19,1: 129 Anm. 78, 137 Anm. 115

- 2,1: 165 Anm. 68

- 2,1,2: 137 Anm. 115

- 2,1,3: 51, 129 Anm. 78, 136

- 2,2: 135 Anm. 105

- 2,2,2-6: 134 Anm. 93

- 2,3: 135 Anm. 100

- 2,3,3: 136 Anm. 114

- 2,11: 135 Anm. 103

- 2,11,4-8: 135 Anm. 103

$-2,11,4: 135$

$-2,14: 135$

- 2,14,9: 135 Anm. 105

- 2,22,2: 137 Anm. 115

- 2,38,3f.: 136 Anm. 110

- 2,38,5: 136 Anm. 111

- 3,10: 139 Anm. 121

- 4,4: 135 Anm. 103

- 4,7,4: 136 Anm. 113

- 4,9: 134 Anm. 93

- 4,17: 134 Anm. 93

- 4,18: 134 Anm. 93

$-5,3 \mathrm{f} .: 135$

- 5,11,2: 139 Anm. 121

- 5,13,1: 129 Anm. 78

- 6,17,4: 136 Anm. 112

Agath.

- 4,23,5: 3
AL

- 210 Shackleton Bailey: 82 Anm. 51

- 259 Shackleton Bailey: 82 Anm. 51

- 260 Shackleton Bailey: 82 Anm. 51

AP

- 2,1,269: 32 Anm. 45

- 3,10: 122 Anm. 67

- 4,1: 77, 81 Anm. 49

$-4,2: 77$

- 5,56,1: 129 Anm. 78

- 5,62,3f.: 129 Anm. 78

- 5,65: 88 Anm. 68

- 5,74: 81 Anm. 49

- 5,144: 81 Anm. 49, 136 Anm. 108

- 5,147: 77, 81 Anm. 49

- 6,56,1: 234 Anm. 108

- 9,77: 85

$-9,198: 3 \mathrm{f}$.

- 9,231: 166 Anm. 70

- 9,375: 166 Anm. 70

- 11,34: 81 Anm. 49

- 11,76: 81 Anm. 49

- 11,298,6f.: 122 Anm. 67

-11,330: 88 Anm. 68

- 11,407: 88 Anm. 68

- 12,37,133: 88

$-12,37,254: 88$

- 12,75-78: 67 Anm. 4

$-12,128: 77$

- 12,220f.: 88 Anm. 68

-13,28: 224 Anm. 77

-65,69: 88

Aphth.

- Prog. 2,5: 165

- 8: 162 Anm. 57

- 8,2: 165 Anm. 67

- 10,1: 158

- 12,1: 178 Anm. 105 u. 106

Apollod.

$-1,3,3: 74$

- 3,1,2: 93 Anm. 93

- 3,9,2: 108 Anm. 38

- 3,10,3: 74

- 3,13,2: 108 Anm. 38

Apul.

- met. 6,24: 224

- 8,7: 231 Anm. 101 
A. $R$.

$-1,1: 215$

$-1,504: 185$

- 1,721-768: 196 Anm. 156

- 1,1135: 149 Anm. 157

-1,1207-1272: 90

$-1,1207-1210: 92$

-1,1229-1232: 90 Anm. 82

-1,1240-1260: 90 Anm. 84, 123

$-1,1263-1272: 91$

- 1,1263f.: 91

- 1,1265-1272: 91

- 1,1266: 91 Anm. 87

$-2,44: 73$

$-2,676 \mathrm{f} .: 52,68$

$-2,678 f .: 68$

$-3,300: 33$

$-3,520: 73$

- 3,1043-1045: 34

- 3,1043: 34

- 4,601: 67 Anm. 5

- 4,771: 67 Anm. 5

- 4,810: 215

- 4,907 f.: 149 Anm. 157

- 4,1366: 67 Anm. 7

- 4,1479f.: 69 Anm. 13

Ar.

- Pax 894-898: 106 Anm. 30

- Th. 988: 234 Anm. 108

Arat.

- 96f.: 194

- 147-151: 35

- 304: 73

- 307: 73

- 540: 73

$-667: 73$

Ath.

- II,3 Kaibel S. 84,7-11: 224

Auson.

- Mos. 169-188: 116

B.

- Fr. *20B,8: 185 Anm. 134

Bion

- I,1f. Beckby: 128

- I,1 Beckby: 133

- I,5 Beckby: 128

- I,7-9 Beckby: 129

- I,7 Beckby: 128, 129, 131

- I,9-11 Beckby: 128

- I,16 f. Beckby: 186 Anm. 136
- I,18f. Beckby: 123 Anm. 70

- I,21 Beckby: 132 Anm. 84

- I,27f. Beckby: 186 Anm. 136

- I,28 Beckby: 133 Anm. 85

- I,29 f. Beckby: 128

- I,31-35 Beckby: 132

- I,31 Beckby: 133 Anm. 85

- I,33 Beckby: 132 Anm. 84

- I,34 Beckby: 128, 129, 131

- I,36 Beckby: 132 Anm. 84

- I,37 f. Beckby: 128, 186 Anm. 136

- I,37 Beckby: 133 Anm. 85

- I,39 Beckby: 133 Anm. 85

- I,42 Beckby: 132 Anm. 84

- I,51f. Beckby: 129

- I,52f. Beckby: 131

- I,54 f. Beckby: 129

- I,60 f. Beckby: 129

- I,61 Beckby: 128

- I,63f. Beckby: 186 Anm. 136

- I,63 Beckby: 128, 133 Anm. 85

- I,64-66: 131

- I,67 Beckby: 128

- I,68 Beckby: 131

- I,69f. Beckby: 186 Anm. 136

- I,70 f. Beckby: 128

- I,71 Beckby: 125, 128

- I,77 Beckby: 128

- I,79 Beckby: 128

- I,85 f. Beckby: 186 Anm. 136

- I,86 Beckby: 133 Anm. 85

- I,87-90 Beckby: 129

- I,89 Beckby: 133 Anm. 85

- I,90 Beckby: 133 Anm. 85

- I,92 Beckby: 128

- I,93 Beckby: 133 Anm. 85

- I,97f. Beckby: 131

- III,1 Beckby: 78, 125, 128 Anm. 77

- III,9,5 Beckby: 132

- III,12 Beckby: 77 Anm. 39

Call.

- Aet. fr. 67,3 Pfeiffer (=79,3 Asper): 107 Anm. 36

- 110,53 Pfeiffer (= 126,11 Asper): 74 Anm. 26

- Cer. 70 f.: 139 Anm. 120

- Dian. 242 f.: 133 Anm. 86

- Epigr. 52 Pfeiffer (=6 Asper $=A P$ 12,230): 87

- Hec. 260,57 Pfeiffer (= 251,16 Asper): 214 Anm. 43

- 277 Pfeiffer (= 279 Asper): 21 Anm. 4 
- Lav. Pall. 218 Anm. 53

$-5,55-69: 36 \mathrm{f}$.

$-5,70-74: 36$

Chor.

- VIII (=Or. 7) Foerster u. Richtsteig: 159 Anm. 45

- XIII (= Dial. 7) Foerster u. Richtsteig: 37 Anm. 64

- XVI (= Dial. 9) Foerster u. Richtsteig: 165, 256 Anm. 84

- XXXIX (= Dial. 24) Foerster u. Richtsteig: 165, 256 Anm. 84

Chrys.

- hom. 2,1,52 in Is. 6,1 (Dumortier): 67 Anm. 5 Claud.

- rapt. Pros. 2,128-136: 81 Anm. 49

- Stil. 2,424-476: 224 Anm. 80

Colluth.

- 1,24: 69 Anm. 9

[D.]

- Or. 61,10: 52 Anm. 52

D. P.

$-830-846: 34$

Drac.

- laud. dei 3,739f.: 249f. Anm. 54

E.

- Ba. 235 f.: 51 Anm. 48

- 455-457: 51 Anm. 48

- Cycl. 563: 149 Anm. 156

- El. 713: 149 Anm. 160

- Hipp. 1213-1248: 141, 148

- IA 152: 149 Anm. 160

- Ion 46: 149 Anm. 160

- 114: 149 Anm. 160

- 161: 149 Anm. 160

- 228: 149 Anm. 160

- Ph. 308 f.: 28 Anm. 31

- 558: 56 Anm. 62

- 1123-1127: 94 Anm. 98

- Suppl. 64: 149 Anm. 160

Eratosth.

- Cat. 26: 89 Anm. 74

- Erig. fr. 3 u. 4: 149

Eustathios Makrembolites

- Hysmine und Hysminias 4,11: 44

- 4,18,8: 44 Anm. 15

Ev. Jo.

$-6,55: 258$

$-11,25: 258$

$-12,28: 258$
Floros und Plaziaflore 805-811: 51 Anm. 48

[Georg. Gramm.]

-1-6: 166 Anm. 71

Georgios Pisides

- De vita humana 90: 24 Anm. 15

Gp.

- 11,29: 234

Gr. Naz.

- carm. 2. 2 (poem.), 4 u. 6: 247

- or. 4 u. 5: 196 Anm. 157

-or. 31,31-33: 159 Anm. 45

- or. 39,4: 247

Gr. Nyss.

- hom. prolog. in Cant. 260 Anm. 105

- hom. 4 in Cant. 260 Anm. 105

Hdt.

- 5,101: 22 Anm. 9

Hecat.

- FGrH 1 fr. 15 Jacoby (= Ath. II 35 AB): 40 Anm. 3

Hermog.

- Prog. 7: 162 Anm. 57

- 7,1: 165 Anm. 67

- 7,14: 165 Anm. 67

- 8,3: 160 Anm. 50

- 10,1: 178 Anm. 106

- 10,6: 186 Anm. 138

Hes.

- Fr. 171,8 Merkelbach u. West: 68 Anm. 8

- 252 Merkelbach u. West: 51

- Sc. 53: 185 Anm. 134

- Th. 154-210: 189

- 275: 69 Anm. 9

- 453-506: 189

- 518: 69 Anm. 9

h. Hom.

- 2 Cer. 91: 185 Anm. 134

- 113: 215

- 316: 185 Anm. 134

- 396: 185 Anm. 134

- 3 Ap. 282: 185

- 3 Ap. 134: 68 Anm. 8

- 4 Merc. 478: 69 Anm. 9

- 5 Ven. 202-212: 84

- 220: 185 Anm. 134

- 26 Bacch. 1: 234 Anm. 108

Him.

- Or. 8: 40 Anm. 6

- 9,19: 224 Anm. 80

- 18,2: 40 Anm. 6 
- 27: 40 Anm. 6

- 44,3: 40 Anm. 6

- 44,4: 158 Anm. 45

$-45,4: 41$

- 47,6: 40 Anm. 6

- 48: 196

- 68: 224 Anm. 80

- 68,5: 40 Anm. 6, 224

- 68,6: 224 Anm. 80

- 68,9: 40 Anm. 6

Hld.

- 4,1,1: 106 Anm. 31

- 4,2,1-4,4,2: 113 Anm. 44

- 5,8,5: 69 Anm. 13

- 10,31,1-10,32,2: 102 Anm. 24

Hom.

- Il. 1,397: 185 Anm. 134

-2,44: 67 Anm. 6

- 2,465: 32

- 2,561: 63 Anm. 69

- 3,184: 63 Anm. 69

- 4,104-147: 235

$-4,148-181: 235$

$-4,193-219: 235$

$-5,265-267: 84$

$-5,500: 215$

$-5,749: 224$

- 6,145: 223 Anm. 73

-6,146-149: 223 Anm. 73

$-8,393: 224$

$-8,433: 224$

-8,555-559: 69 Anm. 13

- 9,152: 63 Anm. 69

- 9,241: 62 Anm. 68

- 9,294: 63 Anm. 69

- 9,505-507: 148

- 10,22: 67 Anm. 6

- 11,599f.: 52 Anm. 52

-13,754: 185

-14,348: 77 Anm. 37

- 16,110: 52 Anm. 52

- 16,680: 125 Anm. 75

- 16,737-749: 115 Anm. 50

- 16,745-749: 115 Anm. 50

- 18,349-353: 125 Anm. 75

- 19,23-33: 139 Anm. 122

- 19,38f.: 125 Anm. 75

- 19,91f.: 148

- 19,350: 68 Anm. 9

- 20,39: 67
$-21,7-28: 115$

- 21,8: 118

- 21,9: 118

- 21,10: 118

- 21,11: 115 Anm. 49, 118

- 21,15: 118

$-21,21: 119$

$-21,25: 118$

$-21,26: 118$

- 21,463-466: 223 Anm. 73

$-22,163 \mathrm{f} .: 105$

- 22,401f.: 28 Anm. 31

- 22,402f.: 124

- 22,405: 124

- 23: 101, 102

- 23,186f.: 125 Anm. 75

$-23,332: 215$

- 23,688f.: 52 Anm. 52

- 23,700-707: 102

$-23,701: 106$

- 23,702: 105

$-23,708$ f.: 102

- 23,709: 107

- 23,710-732: 102

-23,711: 104

- 23,714f.: 104

$-23,714: 104$

$-23,715: 104$

$-23,716: 104$

$-23,724: 104$

$-23,723: 107$

- 23,725-727: 104

$-23,725$ f.: 107

$-23,725: 104$

- 23,726: 104

$-23,727 \mathrm{f} .: 104$

- 23,730: 104

-23,731: 104

- 23,733-739: 102

- 23,736: 104

- 23,739: 104

- 23,740-797: 110

- 23,740-753: 111

- 23,754-777: 111

- 23,754-759: 111

- 23,760-763: 111

-23,761: 112

- 23,762: 112

$-23,766 \mathrm{f} .: 112$

- 23,768-777: 113 
- 23,768-771: 112

- 23,771-777: 112

- 23,778-783: 111

$-23,784: 112$

- 23,785-797: 111

- 23,798-825: 101 Anm. 21

- 23,880: 52 Anm. 52

- 23,884-897: 101 Anm. 21

$-23,885: 105$

- 24,1: 119

- 24,587-590: 125 Anm. 75

- Od. 3,440: 105

- 4,223: 56 Anm. 62

- 5,313-463: 115

- 5,344: 115 Anm. 49

- 5,375: 115 Anm. 49

- 5,399: 115 Anm. 49

- 5,439: 115 Anm. 49

- 6,231: 77 Anm. 37

- 7,276: 115 Anm. 49

- 7,280: 115 Anm. 49

-8,105-255: 101

$-8,193 \mathrm{f} .: 112$

- 8,250: 149 Anm. 157

-8,256-380: 101

- 8,383: 149 Anm. 157

- 9,552: 185 Anm. 134

- 12,413: 115 Anm. 50

- 13,279f.: 133

- 14,352: 115 Anm. 49

- 19,338: 185

- 21: 101

- 21,85: 56 Anm. 62

- 23,158: 77 Anm. 37

- 23,233: 115 Anm. 49

- 23,237: 115 Anm. 49

Hom. Clem.

$-5,9,3: 43$

- 5,15,1-3: 43

Hom. Schol. Od.

- 11,521: 89

Hyg.

- fab. 129: 238 Anm. 122

- 250: 94 Anm. 98

- 273,11: 94 Anm. 98

Jo. Gaz.

-1,119: 32 Anm. 44

- 1,273: 32 Anm. 45

- 1,278: 69 Anm. 13

-1,314-360: 187 Anm. 140
-1,352: 67 Anm. 5

- 2,1-6: 256 Anm. 86

- 2,19: 67 Anm. 7

- 2,96: 28 Anm. 30

- 2,122: 260 Anm. 105

- 2,259-313: 187 Anm. 140

$-2,283-296: 225$

- 2,316: 32 Anm. 44

- anacr. 4 u. 5: 166

Jo. Mal.

- chron. 7,7 Thurn (=178-180 Dind.): 37 Anm. 64

- 12,3 Thurn (= 285 Dind.): 37

Lib.

- Prog. 12,7 Gibson: 225

- Prog. Enkom. 9 Gibson: 165

- Prog. Invec. 8 Gibson: 166, 175

Longus

- 1,9: 135 Anm. 101

- 1,18,1: 51, 136

-1,23: 135 Anm. 101

- 2,1: 135 Anm. 101

- 2,10,1: 136 Anm. 109

- 3,3: 135 Anm. 101

- 3,12: 135 Anm. 101

- 3,24: 135 Anm. 101

- 4,2,3: 234 Anm. 107

- 4,2,5: 135 Anm. 105

- 4,7f.: 136

LXX (Septuaginta)

$-G e$.

$-1,26-30: 261$

$-2,4-7: 261$

$-9,20-27: 39$

Lyc.

-Alex. 40-42: 89 Anm. 77, 107 Anm. 33

Men. Rh.

$-2,369,18-2,370,8: 166$

- 2,370,9-28: 163 Anm. 60

- 2,371,14-17: 162 Anm. 57

- 2,372,12-2,376,24: 164 Anm. 63

- 2,372,21-25: 160 Anm. 49

- 2,368 - 377: 161 Anm. 55

- 2,377,9-30: 165 Anm. 66

Mimn.

- fr. 2,1f.: 223 Anm. 73

- 2,7: 223 Anm. 73

- 2,9: 223 Anm. 73

- 2,15: 223 Anm. 73 
Mosch.

- II,63-71 Beckby: 77, 81 Anm. 49

- III,1-25 Beckby: 132

- III,1 Beckby: 133 Anm. 85

- III,3-8 Beckby: 77, 125 Anm. 74

- III,5 Beckby: 132 Anm. 84

- III,6 Beckby: 133 Anm. 85

- III,8 Beckby: 132 Anm. 84

- III,13 Beckby: 132 Anm. 84

- III,14 Beckby: 133 Anm. 85

- III,15 Beckby: 132 Anm. 84

- III,19 Beckby: 132 Anm. 84

- III,25 Beckby: 132 Anm. 84

- III,27-29 Beckby: 123 Anm. 70

- III,36 Beckby: 132 Anm. 84

- III,45 Beckby: 132 Anm. 84

- III,49 Beckby: 132 Anm. 84

- III,50 Beckby: 132 Anm. 84

- III,57 Beckby: 132 Anm. 84

- III,64 Beckby: 132 Anm. 84

- III,69a Beckby: 132 Anm. 84

- III,75 Beckby: 132 Anm. 84

- III,85 Beckby: 132 Anm. 84

- III,98 Beckby: 132 Anm. 84

- III,99 Beckby: 133 Anm. 85

- III,108 Beckby: 132 Anm. 84

- III,113 Beckby: 132 Anm. 84

- III,114 Beckby: 132 Anm. 84

- III,115-126 Beckby: 131

Musae.

- 55-66: 51 Anm. 45, 256

$-57: 256$

$-58: 256$

$-59: 256$

$-60: 256$

$-62: 256$

Nic.

- Alex. 629: 68 Anm. 9

- Ther. 30: 144

- 158: 196 Anm. 155

- 200: 144

- 238: 196 Anm. 155

- 303: 196 Anm. 155

- 538: 144

- 901-906: 74 Anm. 27

- 901: 144

Nicol.

- Prog. 47-58 Felten: 162 Anm. 57

- 50,7 Felten: 162 Anm. 57

- 59-63 Felten: 158 Anm. 44
- 68,12-17 Felten: 178 Anm. 106

Nonn.

D. 1-5: 99, 156

-1,17: 63 Anm. 71

-1,31: 71 Anm. 20

-1,33: 63 Anm. 71

$-1,37: 99$

- 1,41-44: 95 Anm. 100

$-1,131 \mathrm{f} .: 91$

-1,137-320: 219 Anm. 59

- 1,187: 71 Anm. 20

- 1,224: 220

- 1,252: 69 Anm. 13

-1,318: 67 Anm. 7

$-1,355: 73$

$-1,358: 73$

- 1,378-397: 146 Anm. 137

$-1,385: 254$

- 1,398 - 407: 146 Anm. 137

$-1,409-534: 121$

-1,495: 32 Anm. 45

-1,528: 63 Anm. 71

- 2,1-712: 219 Anm. 59

- 2,81-83: 78 Anm. 41

- 2,126: 32 Anm. 44, 67 Anm. 5

$-2,176: 220$

- 2,197: 63 Anm. 71

- 2,259: 32 Anm. 45

- 2,270: 221 Anm. 65

- 2,328: 220 Anm. 64

- 2,575: 32 Anm. 44

- 2,619: 74 Anm. 26

- 2,636: 69 Anm. 13

$-2,704: 220$

$-3,1: 119$

- 3,67: 149 Anm. 157

- 3,124-183: 178 Anm. 109

- 3,138: 69 Anm. 13

- 3,153f.: 78 Anm. 42

- 3,162f.: 78 Anm. 42

- 3,218: 32 Anm. 44

- 3,248-256: 223

- 3,248: 223 Anm. 73

- 3,249-252: 223 Anm. 73

$-3,255: 263$

- 3,259: 83 Anm. 55

$-3,263: 186$

- 3,381: 220 Anm. 64

- 3,406: 185 Anm. 134

- 4,2: 67 Anm. 5, 71 Anm. 20 
- 4,87: 67 Anm. 4

- 4,126-142: 51

- 4,126f.: 136 Anm. 108

- 4,130: 196 Anm. 155

- 4,133f.: 78 Anm. 43

- 4,137: 68 Anm. 8

- 4,238-241: 67 Anm. 4

$-4,252: 255$

- 4,348-355: 230 Anm. 99

- 5,1-34: 230 Anm. 99

$-5,49: 119$

- 5,103-107: 94 Anm. 95

- 5,135-189: 135 Anm. 103, 177

- 5,184: 69 Anm. 13

- 5,270-273: 230 Anm. 99

- 5,287-551: 147 Anm. 148

- 5,304-325: 26 Anm. 21

- 5,362: 74 Anm. 26

- 5,476-488: 26 Anm. 21

- 5,562-565: 19 f. Anm. 2

- 5,585-589: 26 Anm. 21

- 5,601-610: 26 Anm. 21

$-6: 156$

$-6,1-108: 219$

- 6,7: 67 Anm. 7

- 6,17: 28 Anm. 31

- 6,43: 74 Anm. 26

$-6,84: 194$

$-6,102: 194$

- 6,107: 32 Anm. 44

- 6,148: 149 Anm. 157

$-6,163-205: 40$

$-6,169-173: 82$

- 6,184: 67 Anm. 7

$-6,229-388: 218$

$-7-12: 156$

$-7,1-109: 220$

$-7,1-3: 218$

$-7,7-21: 222$

$-7,11: 222$

$-7,13: 222$

$-7,17: 222$

$-7,18: 222$

$-7,29-66: 222$

$-7,71-105: 237$

- 7,73-105: 58 f., 222

- 7,76-78: 61, 87 Anm. 65

$-7,77: 60$

$-7,84: 60$

$-7,86: 60$
- 7,87: 60, 63 Anm. 71

$-7,89: 60$

$-7,90: 60$

$-7,91: 60$

$-7,92: 61$

- 7,100: 60, 63 Anm. 71, 233 Anm. 107

$-7,104: 60$

- 7,118: 91

- 7,129-135: $60 \mathrm{f}$.

- 7,132: 61, 63 Anm. 71

$-7,133: 61$

- 7,134f.: 87 Anm. 65

- 7,135: 61

- 7,161-170: 230 Anm. 99

- 7,171-279: 26 Anm. 21

$-7,178$ f.: 220

$-7,222-224: 51$

-7,228: 28 Anm. 30

- 7,236-252: 51

- 7,241: 33 Anm. 54

$-7,303: 260$

- 7,325-328: 61

- 7,327: 61, 63 Anm. 71, 233 Anm. 107

$-7,334: 61$

$-7,335: 61$

- 7,337f.: 87 Anm. 65

$-7,338: 61$

- 7,339: 61, 63 Anm. 71

- 7,341: 61 Anm. 66, 233 Anm. 107

$-7,345: 61$

- 7,384: 33 Anm. 54

$-8,5$ f.: 220

-8,10: 63 Anm. 71

-8,12: 63 Anm. 71

$-8,32 \mathrm{f} .: 220$

$-8,91-102: 85$

$-9,11-15: 189,221$

- 9,12: 63 Anm. 71

$-9,25: 28$

-9,93: 67 Anm. 6

-9,111-131: 62, 226 Anm. 92

$-9,116: 62$

$-9,117: 62$

$-9,118: 62$

$-9,119: 62$

$-9,120-124: 62$

- 9,120: 62

- 9,121: 109 Anm. 41

- 9,122: 63 Anm. 71, 233 Anm. 107

$-9,123: 62$ 
$-9,126: 62$

- 9,127: 62

$-9,130: 62$

- 9,131: 62

- 9,195: 74 Anm. 26

-9,243-321: 20

- 9,263: 63 Anm. 71

- 9,275-289: 238 Anm. 126

-9,283-289: 56 Anm. 61

- 9,286: 56 Anm. 61

- 9,287: 186

-9,308: 32 Anm. 44

- 10,1-138: 20

$-10,120-125: 20$

- 10,126-138: 20

- 10,139-174: 19, 69, 90, 135 Anm. 105, 166, 179, 199, 231

- 10,139-142: 205

- 10,139-141: 20

- 10,139: 135, 201

$-10,140: 21,29$

- 10,141-174: 202

- 10,141-147: 21

$-10,141-146: 73$

$-10,141-144: 29$

- 10,141f.: 35, 205, 208

- 10,141: 21, 28, 32, 71 Anm. 19

- 10,142 f.: 36

$-10,143: 33$

- 10,144f.: 23

$-10,144: 29,135$

$-10,145: 29,31$

$-10,146: 28,118$

$-10,147: 29$

- 10,148-174: 232

-10,148-168: $23 \mathrm{f}$.

- 10,148f.: 24

$-10,148: 30$

- 10,149: 29, 30, 32

- 10,150-152: 24

- 10,150: 29, 30, 31, 118

- 10,151: 29

$-10,152: 29,30,34$

$-10,153-157: 24$

$-10,153: 29$

- 10,154: 29

- 10,155: 29, 30

- 10,156: 29

- 10,157: 28, 29

$-10,158-163: 24$
- 10,158: 29, 30

- 10,160: 24 Anm. 15, 29

- 10,161: 29, 30

- 10,162: 29, 30

- 10,163: 29, 31

-10,164-168: 24

$-10,164: 29$

$-10,165: 29,30$

- 10,167: 29, 30

- 10,166: 29, 30

- 10,168: 29, 30

-10,169-174: $24 \mathrm{f}$.

$-10,169: 25,30$

$-10,170: 29,30$

-10,171-174: 29

- 10,171f.: 201, 255

$-10,171: 28,29,118$

$-10,172$ f.: 220

$-10,172: 28$

- 10,173: 29, 71 Anm. 19

- 10,174: 28, 30, 119

$-10,175-321: 199$

- 10,175-192: 50, 54, 69, 136, 162, 173

Anm. 80, 180, 214, 229, 256

-10,175-187: 217

- 10,175-177: 50, 201

- 10,176: 50, 54 Anm. 56, 214, 234, 256

- 10,177: 54 Anm. 58, 234

- 10,178-192: 202

- 10,178: 50, 51, 55 Anm. 60, 136, 162, 180, 214

$-10,179$ f.: 51, 214

- 10,179: 28, 52, 90, 128, 173 Anm. 80, 180, 214, 234

$-10,180: 256$

$-10,181-187: 51$

$-10,181-184: 236$

- 10,181: 51, 136, 163, 180, 214, 234

- 10,182: 51, 54 Anm. 56, 163, 180, 214

$-10,184: 71,214$

- 10,185-192: 52 Anm. 52

- 10,185: 54 Anm. 56, 69, 214, 256

$-10,186$ f.: 69

- 10,186: 180, 214

- 10,187: 69 Anm. 13, 214, 256

- 10,188: 51, 52, 136, 163, 214, 236, 256

- 10,189f.: 51

- 10,189: 51, 136, 214

- 10,190: 52, 136, 163, 214, 255

- 10,191f.: 51, 69

- 10,191: 206 Anm. 18 
- 10,192: 69, 214

- 10,193-216: 52, 71, 163

- 10,196-216: 11, 67, 156, 157 Anm. 39

- 10,196-202: 163

- 10,198-200: 67

- 10,198: 206 Anm. 18

- 10,199: 67, 122

- 10,200: 67 Anm. 4

- 10,203f.: 67

- 10,203: 206 Anm. 18

$-10,204: 67$

$-10,205-207: 67$

$-10,205: 67$

- 10,206: 67

-10,207: 67

- 10,208-211: 163

$-10,208$ f.: 163

- 10,208 u. 213: 206 Anm. 18

- 10,209: 163

- 10,210-213: 206

$-10,210: 163$

- 10,211: 163

$-10,212: 163$

$-10,213: 163$

$-10,214-216: 81$

$-10,214: 163$

$-10,217-277: 37,95$

- 10,217-249: 164

- 10,219-277: 201

- 10,220: 164, 206 Anm. 18, 226

- 10,221: 206 Anm. 18

- 10,222: 206 Anm. 18

- 10,222-225: 227

- 10,223: 164

$-10,224: 164,228$

$-10,226-229: 91$

- 10,226: 202, 206 Anm. 18

- 10,230-242: 121

$-10,230-234: 95$

- 10,230: 91, 164, 206 Anm. 18

- 10,231f.: 227

- 10,232: 201

- 10,234: 149 Anm. 157

- 10,235: 206 Anm. 18

- 10,238-242: 146

- 10,238-241: 227

$-10,238$ f.: 164

- 10,238: 206 Anm. 18

- 10,293: 55 Anm. 60

- 10,242: 90 Anm. 78
- 10,243: 206 Anm. 18

- 10,245: 90 Anm. 78, 122

$-10,250-263: 84$

- 10,250-259: 95

- 10,250-255: 74, 85

$-10,250$ f.: 164, 201

$-10,250: 201,228$

$-10,251: 228$

- 10,256-263: 83, 158 Anm. 43

- 10,256-259: 85

$-10,257: 201$

- 10,260-263: 85, 203

$-10,261: 83$

$-10,262: 83$

- 10,263: 55 Anm. 60, 83

- 10,264-266: 14

- 10,266: 136 Anm. 109

- 10,267-269: 162

- 10,267: 206 Anm. 18

- 10,269: 206 Anm. 18

- 10,274f.: 206 Anm. 18

- 10,278-289: 122 f., 162

- 10,278-288: 121 Anm. 63

- 10,287: 123

- 10,286: 55 Anm. 60

- 10,288: 90 Anm. 78

- 10,290: 201

- 10,292-320: 146, 156

- 10,292: 146

- 10,293: 201, 206

- 10,294: 205

- 10,295: 206

- 10,297: 206

- 10,307: 201

- 10,302: 146

$-10,304: 146$

$-10,309-320: 85,86$

- 10,309: 146

- 10,310-320: 206

- 10,310 f.: 206

- 10,311: 214 Anm. 43

- 10,312: 121

$-10,314: 146$

- 10,317: 55 Anm. 60

- 10,318: 201

- 10,320: 86, 146

- 10,321-430: 164

- 10,321-11,55: 199

$-10,322-11,55: 235$

$-10,322-325: 121$ 
- 10,325-329: 201

- 10,326: 214 Anm. 43

- 10,327f.: 206 Anm. 18

- 10,327: 201

- 10,329: 206 Anm. 18, 228

- 10,330-382: 136 Anm. 110

$-10,330-338: 105$

- 10,330-332: 102, 202

- 10,330: 206 Anm. 18, 214 Anm. 43

- 10,333-338: 102

- 10,335: 105 Anm. 28, 149 Anm. 157, 227

Anm. 93

- 10,336-338: 80, 255

- 10,336: 104, 106

$-10,337$ f.: 108

- 10,337: 71 Anm. 19, 122

$-10,338: 106$

$-10,339-430: 101$

- 10,339-372: 102, $103 \mathrm{f}$.

- 10,339: 104, 105, 106

- 10,340: 104, 229

- 10,341: 104

- 10,342: 104

- 10,343: 104

$-10,344: 104$

- 10,345f.: 106

$-10,346: 104$

- 10,347-350: 207

$-10,348-350: 229$

$-10,351-356: 104$

$-10,352-354: 107$

$-10,352: 106$

- 10,353: 55 Anm. 60

- 10,354 f.: 104

- 10,354: 106

- 10,356: 24 Anm. 15

$-10,357 \mathrm{f} .: 108$

- 10,357: 106

$-10,358:$ 106, 202

-10,360: 106

- 10,364: 105 Anm. 28, 106, 108

- 10,366: 107

- 10,368: 71 Anm. 19

$-10,369$ f.: 167

- 10,369: 109, 229

$-10,372: 104$

$-10,373-382: 102$

- 10,373-378: 89 Anm. 77

- 10,373: 107, 206 Anm. 18

- 10,374-377: 107
- 10,376: 24 Anm. 15

- 10,378-382: 109

-10,379: 227 Anm. 93

- 10,380-382: 202, 216

- 10,380: 104

- 10,382: 104, 109

$-10,383-412: 110$ f., 216

- 10,383-397: 111

- 10,386-392: 228

$-10,386: 112,122$

- 10,387: 112

- 10,388: 112

- 10,390 f.: 112

- 10,390: 71 Anm. 19

- 10,393-397: 112, 203

$-10,394: 217$

$-10,396: 217$

- 10,397: 201, 228

- 10,398-412: 111

$-10,399: 146$

$-10,400-430: 233$

$-10,400-405: 216$

- 10,400: 217 Anm. 52

- 10,401: 55 Anm. 60, 217 Anm. 52, 233

$-10,402-412: 203$

- 10,402-409: 111

- 10,405: 217 Anm. 52

- 10,407: 217

$-10,410-412: 112$

- 10,411: 112

- 10,412: 69 Anm. 13

-10,413-424: $113 \mathrm{f}$.

-10,413: 55 Anm. 60

- 10,414: 90 Anm. 78, 114, 123

- 10,416: 55 Anm. 60

-10,418: 217 Anm. 52

$-10,422$ f.: 233

- 10,422: 217

-10,423: 217

- 10,424: 55 Anm. 60, 217

$-10,425-430: 114$

$-10,425$ f.: 112

- 10,427-430: 111

- 10,427 f.: 90 Anm. 78, 123

- 10,427: 233

$-11,1-55: 26,101,116-118,164$

$-11,1-6: 227$

- 11,2: 227

- 11,3: 204

-11,6: 227 
- 11,7-42: 157 Anm. 39

- 11,10: 56 Anm. 60

-11,11: 203

- 11,14-16: 206

- 11,14: 203

- 11,15: 229

- 11,18: 55 Anm. 60

- 11,19: 203

- 11,20f.: 73

- 11,21: 136f. Anm. 115, 203

- 11,22-27: 72

- 11,22: 73, 118

- 11,23: 73

- 11,24: 203

-11,25: 55 Anm. 60, 236

- 11,26f.: 73

- 11,26: 137 Anm. 115

- 11,27: 118

- 11,31: 118

- 11,36f.: 202

-11,38: 203

-11,39: 56 Anm. 60, 118

-11,40: 202

- 11,43-55: 90, 203

-11,44: 55 Anm. 60

- 11,45f.: 118

-11,45: 203, 216, 217

-11,48: 217

-11,49: 217

- 11,50: 217

-11,51: 203, 217

-11,53: 55 Anm. 60, 203, 217

- 11,55: 203, 217

$-11,56-223: 199$

-11,56-70: 28, 71f., $228 \mathrm{f}$.

- 11,56f.: 201

-11,57: 55 Anm. 60

- 11,58: 109 Anm. 41

-11,60: 206 Anm. 18

-11,63-70: 201

-11,64: 228

- 11,66f.: 228

-11,66: 201

-11,68: 228

- 11,69f.: 228

-11,69: 206 Anm. 18

-11,74-80: 157 Anm. 39

$-11,74: 201$

-11,78-80: 201

-11,78: 228
$-11,79: 228$

- 11,80: 228

-11,81: 55 Anm. 60

- 11,83-98: 13, 207

-11,83: 206 Anm. 18

-11,84-93: 201 Anm. 8

- 11,84: 55 Anm. 60

- 11,87: 201

- 11,89: 24 Anm. 15

- 11,91-93: 230

- 11,92: 201

- 11,99-112: 164

- 11,99 f.: 164, 201

- 11,102: 136 Anm. 111, 206 Anm. 18

- 11,103-112: 68, 227

$-11,103 \mathrm{f} .: 227$

- 11,103: 206 Anm. 18

- 11,104f.: 164

- 11,104: 68

$-11,105$ f.: 227

-11,105: 227

- 11,106: 206 Anm. 18

- 11,107-112: 227

$-11,111 \mathrm{f} .: 68$

-11,112: 206 Anm. 18

- 11,113-223: 137, 164

- 11,113-154: 147

$-11,113: 203 \mathrm{f}$.

-11,114: 201

- 11,116: 56 Anm. 60

- 11,118-154: 157

- 11,119-129: 227

$-11,120: 228$

$-11,126: 228$

- 11,129: 228

- 11,130-154: 206

$-11,130-135: 203$

$-11,130 \mathrm{f} .: 93 \mathrm{f}$.

$-11,130: 206$

- 11,134-139: 85, $86 \mathrm{f}$.

- 11,136: 56 Anm. 60, 240

- 11,139-146: 137

- 11,143-146: 94

- 11,143: 74 Anm. 26

-11,145: 203

- 11,147-223: 228

-11,148: 203

$-11,150$ f.: 206

$-11,152-154: 92$

-11,155-184: 28 
- 11,156: 201

-11,161-166: 26, 202, 207, 230

-11,166: 63 Anm. 69

-11,167-184: $229 \mathrm{f}$.

- 11,175-178: 80, 202

$-11,175: 81,255$

- 11,176: 71 Anm. 19, 81, 196 Anm. 155, 255

- 11,177: 81, 255

- 11,178: 81, 255

- 11,179-181: 202

- 11,188-223: 53, 91, 137-139

- 11,189: 90 Anm. 79, $203 f$.

- 11,190: 56 Anm. 60, 91

- 11,193: 201

- 11,195: 201

- 11,212 f.: 139 Anm. 120

$-11,214-223: 148$

- 11,216: 201

- 11,218: 24 Anm. 15

- 11,222f.: 207, 230

- 11,224-350: 41, 53 Anm. 55, 137, 199

$-11,224-252: 123 \mathrm{f}$.

$-11,224-226: 139$

- 11,224f.: 90, 148, 203

- 11,224: 124, 203

- 11,225-312: 139

- 11,225: 56 Anm. 60, 124

- 11,226-230: 89, 125, 203

- 11,226: 91

- 11,228: 90, 128

- 11,229: 91

$-11,230-252: 230$

- 11,230 f.: 124, 203

$-11,230: 203$

- 11,232-241: 125

- 11,235-237: 202

$-11,235: 255$

-11,237: 255

- 11,238f.: 125

- 11,238: 201

- 11,241-253: 139

- 11,241-243: 125

$-11,243: 125$

$-11,244-248: 125$

- 11,244: 124, 203

- 11,246: 124

- 11,248f.: 123 Anm. 70

$-11,248: 124$

$-11,250-252: 128$

- 11,250: 125
- 11,252: 74 Anm. 26

- 11,253-312: $126-128$

- 11,255-263: 75, 77, 93, 129, 158 Anm. 43

$-11,255-350: 121,235$

- 11,256: 75, 228

- 11,257: 93 Anm. 95

- 11,258f.: 93

- 11,258: 90 Anm. 79, 123

- 11,261: 202

- 11,262: 122

- 11,263: 76

- 11,264-270: 129, 139, 207 Anm. 21, 230

$-11,270-275: 129$

$-11,271-275: 83$

- 11,271f.: 201

$-11,271: 83$

- 11,272f.: 203

$-11,272: 83$

$-11,273: 83$

$-11,274: 83$

$-11,275: 83$

- 11,276-279: 129, 139

- 11,277: 55 Anm. 60

- 11,280-287: 128

$-11,284: 128$

-11,286: 128, 202

- 11,287-295: 137

$-11,288-300: 129$

- 11,288: 228

- 11,289-295: 85

- 11,293-295: 87

- 11,294: 228

- 11,295: 203, 240

-11,296: 129, 201

-11,300: 228

-11,301: 227

-11,302: 228

$-11,303: 228$

- 11,304: 129

-11,306: 56 Anm. 60

- 11,307: 129

$-11,308 \mathrm{f} .: 202$

- 11,312: 22 Anm. 10, 202

- 11,313-350: $129 \mathrm{f}$.

- 11,313f.: 203

- 11,315-350: 139

-11,316: 16, 56 Anm. 60, 76

- 11,321-324: 81

- 11,322: 202 Anm. 10

- 11,325-327: 71 Anm. 19, 131 
- 11,325: 236

- 11,326: 202 Anm. 10

-11,327-333: 131

-11,327: 56 Anm. 60

- 11,329f.: 76

- 11,331-334: 146, 228

- 11,333f.: 131

- 11,333: 131, 201

-11,335-350: 131

-11,337-350: 201

- 11,337f.: 228

-11,338: 201

- 11,341f.: 228

- 11,344f.: 228

- 11,346: 228

- 11,349f.: 228

- 11,349: 201

-11,350: 11

-11,351-12,397: 235

- 11,351-485: 53 Anm. 55, 199

- 11,351-368: 136 Anm. 114

- 11,351: 122, 136 Anm. 112

- 11,353: 201

- 11,354: 228 Anm. 94

- 11,356-481: 212

$-11,356-368: 122$

- 11,356-362: 76 Anm. 33

$-11,358 \mathrm{f.:}$ 11, 122

$-11,363-365: 76,212$

$-11,366-368: 122,207,230$

- 11,366: 260

- 11,368: 136 Anm. 112

- 11,369-481: 119, 199

- 11,369-399: $212 \mathrm{f}$.

$-11,369: 215$

- 11,370-384: 51 Anm. 45, 217

-11,370: 90 Anm. 81, 128, 214

- 11,371: 202, 215

- 11,372: 214

- 11,373-376: 71 Anm. 19

- 11,373: 214

- 11,374 f.: 214, 215

- 11,375: 214

$-11,376: 214$

- 11,377f.: 214, 129 Anm. 78

- 11,378: 69 Anm. 13, 214

-11,379-383: 202

- 11,384-399: 217

- 11,384-396: 215

- 11,384: 214, 215
- 11,385: 214, 215

- 11,387: 215

-11,388: 215

- 11,389: 214

- 11,390: 92 Anm. 91, 215

- 11,391: 214

- 11,392: 214, 215

-11,393: 214

- 11,395: 214, 215

- 11,396: 90 Anm. 79, 123, 214

- 11,397: 214, 215

- 11,398f.: 214 Anm. 43

-11,399: 202

$-11,400-426: 26,90,215 \mathrm{f}$.

- 11,400-405: 119, 212

- 11,400: 202 Anm. 9, 217

- 11,401: 217

- 11,402: 202 Anm. 9, 217

- 11,403: 216 f., 217

- 11,404: 217

$-11,405: 217$

- 11,406-426: 119, 212

$-11,406: 216$

- 11,409: 217

- 11,412: 202 Anm. 9, 217, 217

- 11,414: 217

- 11,416: 217

- 11,419: 217

- 11,420: 217

- 11,427-479: 202

- 11,427: 90 Anm. 79, 94, 123

- 11,431-460: 121

-11,431-438: 82 Anm. 51

$-11,431: 75$

- 11,433: 82 Anm. 51

-11,435: 82 Anm. 51

- 11,436: 94

-11,437: 90 Anm. 79, 94, 123

- 11,449: 92 Anm. 91

- 11,454: 92 Anm. 91

- 11,455-457: 75

- 11,460: 122

- 11,463: 136 Anm. 113

- 11,465-474: 121

-11,465: 28 Anm. 31

- 11,468: 122

- 11,470-474: 140

- 11,475f.: 157 Anm. 39

- 11,478: 24 Anm. 15

- 11,482-485: 180 
- 11,483: 122

$-11,484: 11$

- 11,485-12,117: 11, 53 Anm. 55, 199

- 11,485-521: 30, 135, $181 \mathrm{f}$.

-11,485-487: 182, 204

- 11,485: 180,187

- 11,488-494: 182

- 11,488: 185

- 11,490: 67 Anm. 6

- 11,495-500: 182

- 11,496f.: 109 Anm. 41

- 11,497: 186

- 11,498: 185 Anm. 134

- 11,501-508: 182

- 11,505f.: 146 Anm. 142

$-11,506: 186$

- 11,509-519: 182

- 11,510f.: 202

- 11,513 f.: 71 Anm. 19

- 11,515-519: 202

$-11,515: 184$

-11,516: 63 Anm. 69

- 11,517: 184

- 11,516: 184

- 11,519: 184, 233

- 11,520 f.: 182, 185, 208

- 12,1-117: 25

- 12,1-20: 187, $208 \mathrm{f}$.

$-12,1 \mathrm{f} .: 204$

$-12,2: 210$

$-12,3: 210$

$-12,5: 210$

$-12,7 \mathrm{f} .: 204$

$-12,9: 210$

- 12,10: 121

- 12,12: 71 Anm. 19

-12,14: 204

$-12,15-20: 210$

$-12,15 \mathrm{f} .: 204$

-12,17: 16

- 12,21: 184 Anm. 132

- 12,23-28: 146, 187

$-12,23: 146,240,260$

$-12,25: 210$

$-12,26: 146$

- 12,29-40: 195

$-12,29-35: 187$

$-12,30-32: 204$

$-12,30: 210$

-12,34: 192, 209, 210
$-12,35: 192$

$-12,36-40: 187$

$-12,36: 210$

$-12,37-40: 87$

$-12,38: 210$

$-12,41-113: 35$

$-12,41-55: 188$

$-12,41-51: 209$

$-12,41-43: 189$

$-12,44: 209$

$-12,46$ f.: 204

$-12,52-63: 209$

$-12,55-63: 188$

- 12,54 f.: 189

-12,56: 189, 204

-12,58: 28 Anm. 30

- 12,59-63: 204

$-12,64-117: 243$

$-12,64-102: 135,148,190 f$.

$-12,64-69: 190$

$-12,67: 192,196$

- 12,68: 192

-12,69: 192, 209

- 12,70: 193, 204, 210

$-12,74: 193,210$

-12,76: 193, 210

-12,79: 204

- 12,81: 193, 210

-12,82: 204

- 12,84: 204

$-12,86: 193,210$

$-12,88: 204$

$-12,89: 193,210$

$-12,90-96: 190$

$-12,90-95: 35$

$-12,90 \mathrm{f} .: 204$

-12,91: 35, 210

-12,92: 209

- 12,94: 193

- 12,95: 193

-12,96: 192, 204, 209

- 12,97-102: 204, 233

$-12,98: 210$

$-12,100: 210$

- 12,102: 55 Anm. 60, 63 Anm. 69

-12,103-117: 87, $194 \mathrm{f}$.

$-12,103-113: 85$

$-12,103 f .: 204$

$-12,105: 195$

$-12,108: 195$ 
-12,109: 234

$-12,110-113: 195,202,204,210$

$-12,110: 210$

$-12,114: 195$

- 12,115 -117: 204 Anm. 13

$-12,116 \mathrm{f} .: 209$

- 12,117-137: 41, 53 Anm. 55, 78, 131 f., 199

$-12,117-123: 132$

$-12,117-119: 133$

$-12,117 \mathrm{f} .: 11,122$

$-12,119: 132$

- 12,120: 133 Anm. 85

-12,123-137: 132

$-12,123: 132$

$-12,124-130: 202$

- 12,127: 22 Anm. 10, 132

-12,133-137: 202

$-12,133: 132$

$-12,134: 133$

$-12,136: 132$

- 12,138-172: 53 Anm. 55, 167 f., 199

$-12,138: 12$

$-12,139: 11$

-12,142-171: 162

$-12,142-146: 168$

- 12,143: 202 Anm. 10

- 12,144: 168 Anm. 73, 240, 262

$-12,145$ f.: 230

-12,145: 55 Anm. 60, 168 Anm. 73

-12,146: 206

$-12,147-153: 71,148,169,254$

$-12,148: 204,228$

-12,149: 149, 206

$-12,150: 149,204,206$

-12,151: 149, 204, 228

-12,152: 149, 204, 206

-12,153: 56 Anm. 60, 63 Anm. 69

- 12,154-157: 77

$-12,154$ f.: 169,230

-12,155: 202, 206

-12,156-160: 169

-12,156: 90 Anm. 80, 123

$-12,157: 202$

-12,158f.: 87 Anm. 65

-12,160: 206

$-12,162-166: 169$

$-12,162: 206$

$-12,165 f .: 202$

- 12,167-172: 169

-12,167: 56 Anm. 60, 168
$-12,168: 202,206$

$-12,169: 206$

$-12,171 \mathrm{f} .: 16$

$-12,171: 206,258$

$-12,173-206: 169,199$

-12,173-187: 53f., 202

- 12,173: 54 Anm. 58

-12,175: 28, 55 Anm. 60, 54 Anm. 56 u. 58

- 12,176-184: 55 Anm. 59

$-12,179: 54,169,175$

$-12,180: 54$

- 12,181: 54 Anm. 56, 63 Anm. 69

- 12,185-187: 54, 169

- 12,186: 54 Anm. 56 u. 58, 63 Anm. 69

- 12,187: 109 Anm. 41

- 12,188-192: 54, 202, 233

- 12,188: 54 Anm. 58, 175

-12,189: 54 Anm. 58

- 12,190: 54 Anm. 58

- 12,191f.: 109 Anm. 41

- 12,192: 54 Anm. 58, 186

- 12,193-206: 54 f., 144, 169, 202, 231

-12,207-291: 145, 169-172, 200, $255 \mathrm{f}$.

- 12,207-289: 52, 157 Anm. 39, 159, 162

-12,207-211: 202

-12,207-209: 77

- 12,207: 56 Anm. 60, 173, 174

- 12,209-211: 173 Anm. 79

$-12,209: 159$

$-12,210: 159$

$-12,211: 173,258$

- 12,212-231: 173

- 12,212: 56 Anm. 60, 173

- 12,213: 173 Anm. 77

- 12,214: 173 Anm. 77

- 12,216: 173 Anm. 77

- 12,217: 202 Anm. 10

- 12,219 f.: 173 Anm. 78

-12,219: 173, 258

- 12,220: 202 Anm. 10

- 12,221: 173 Anm. 77

$-12,222 \mathrm{f} .: 174$

- 12,222: 173 Anm. 77 u. 80, 258

-12,223: 173 Anm. 77 u. 80

$-12,224$ f.: 159

- 12,224: 173 Anm. 79, 202

- 12,225-228: 173

- 12,225: 173 Anm. 77

- 12,226: 173

- 12,227: 173 Anm. 77 
- 12,228: 173 Anm. 77

- 12,229-231: 173, 207 Anm. 21

- 12,229: 173 Anm. 77

- 12,230: 173 Anm. 77 u. 80

- 12,231-244: 159, 202

- 12,231-233: 173

- 12,231: 173 Anm. 77

- 12,232: 160, 173 Anm. 77 u. 80

- 12,233: 160, 173 Anm. 77 u. 80

$-12,234: 160$

-12,235: 159, 160

- 12,237-241: 77

- 12,237-239: 159, 173 Anm. 79

- 12,237: 160, 173 Anm. 77 u. 80

- 12,239: 160, 173 Anm. 80

- 12,240: 160, 173 Anm. 80

- 12,241: 160, 173 Anm. 77 u. 80, 207

- 12,242: 160, 207

$-12,243: 160$

- 12,244: 160, 173 Anm. 77 u. 80, 207

- 12,245-279: 202

- 12,245-269: 160, 174

- 12,246: 109 Anm. 41

- 12,248-250: 230

- 12,249 f.: 172

- 12,250: 56 Anm. 60, 173

- 12,252: 63 Anm. 69

- 12,254: 173 Anm. 79

- 12,253: 173 Anm. 80

- 12,255: 173 Anm. 79

- 12,257: 173 Anm. 79

- 12,258: 71 Anm. 19

- 12,259-261: 174

- 12,259: 174

- 12,260 f.: 173 Anm. 79

- 12,260: 173 Anm. 80

- 12,261: 173 Anm. 80

- 12,263-269: 174

- 12,263: 173 Anm. 80

- 12,265-269: 175

- 12,268: 173 Anm. 80

- 12,270 f.: 173

-12,270: 56 Anm. 60, 173

- 12,271: 173 Anm. 77 u. 80, $207 f$.

- 12,272-284: 135 Anm. 105, 173

- 12,276: 173 Anm. 77

- 12,277: 173 Anm. 80

- 12,278: 173 Anm. 80

- 12,280: 128, 173 Anm. 80

- 12,281: 173 Anm. 77
- 12,285-289: 173, 208

- 12,285: 208

- 12,286: 173 Anm. 80

- 12,288: 173 Anm. 77

- 12,289: 71 Anm. 19, 122

- 12,291: 71 Anm. 19

-12,292-397: 141, 174, 200

- 12,292-318: $142 \mathrm{f}$.

-12,292: 63 Anm. 69

$-12,293$ f.: 211

$-12,293: 145$

- 12,294-303: 174

$-12,294: 141$

-12,295-318: 205

$-12,304-313: 174$

- 12,314-318: 135 Anm. 105, 174

$-12,315: 144$

- 12,317: 63 Anm. 69, 136 Anm. 105

$-12,319-336: 143$

$-12,319-328: 174$

$-12,324: 205$

$-12,328-339: 26$

$-12,328-336: 174$

$-12,328-330: 211$

$-12,331-334: 205$

$-12,335 \mathrm{f} .: 205$

$-12,336: 211$

$-12,337-362: 174$

$-12,337-344: 144$

$-12,337-341: 81$

$-12,340: 144$

$-12,345-362: 231 \mathrm{f}$.

- 12,350: 146, 149 Anm. 157

$-12,360-362: 211$

$-12,360: 205$

-12,363-393: 144, 174

- 12,363-379: 107 Anm. 34, 232

$-12,363: 232$

-12,367: 232

$-12,369: 232,240$

$-12,371: 232$

$-12,373: 205$

$-12,375: 205$

$-12,376: 232$

$-12,380$ f.: 205

$-12,382-393: 232$

$-12,382$ f.: 146

-12,397: 205, 211

$-13-40: 156$

$-13-24: 99$ 
- 13-19: 100 Anm. 17

$-13-14: 33$

$-13,23 \mathrm{f} .: 221$

- 13,50: 99

- 13,83-121: 234

- 13,84f.: 51 Anm. 45

-13,84: 234

$-13,85: 234$

- 13,90-92: 51 Anm. 45, 234

- 13,101: 28 Anm. 30

- 13,360: 149 Anm. 157

-13,464-510: 201

- 13,464-473: 22

$-13,465: 31$

- 13,468-470: 22 Anm. 12

- 13,469: 63 Anm. 69

- 13,472 f.: 22 Anm. 11

- 13,472: 22 Anm. 10

- 13,499: 149 Anm. 156

- 13,563-565: 203 Anm. 10

-14,99: 233

- 14,102: 63 Anm. 69

- 14,215: 233

- 14,243: 233 Anm. 107

- 14,255: 63 Anm. 69

- 14,284: 63 Anm. 69

- 14,328: 63 Anm. 69

- 14,354: 63 Anm. 69

-14,392: 233 Anm. 104

- 14,394: 63 Anm. 69

- 14,411-437: 262

- 14,419-437: 174

$-14,423: 174$

- 14,424-426: 174

- 14,427-429: 174

- 14,430-437: 85, 174

$-15-16: 133$

- 15,1-118: 262

$-15,160-166: 234$

$-15,161 \mathrm{f} .: 235$

- 15,169-422: 121

- 15,170: 71 Anm. 19

- 15,186: 74 Anm. 26

- 15,204-206: 51 Anm. 45

- 15,204: 71 Anm. 19

- 15,210: 51 Anm. 45

- 12,220-243: 51 Anm. 45

- 15,224-226: 136 Anm. 108

$-15,353: 82$

- 15,370-422: 41 Anm. 9
- 16,1-249: 121

- 16,7: 33 Anm. 54

- 16,72-81: 136 Anm. 108

- 16,78-81: 129 Anm. 78

- 16,117: 78 Anm. 44

- 16,272: 63 Anm. 69

-16,285: 32 Anm. 44

- 16,307: 68 Anm. 9

- 16,374-378: 58

- 16,378: 57 Anm. 65

- 16,397: 220 Anm. 64

- 17,12: 69 Anm. 13

- 17,21: 233

- 17,32-86: 121

- 17,70: 149 Anm. 157

$-17,74-80: 85,175$

-17,74-77: 87 Anm. 65

- 17,172-175: 175

- 17,187: 68 Anm. 8

- 17,263: 63 Anm. 69

-17,271-286: 145 Anm. 137

- 17,296: 63 Anm. 69

- 17,352: 233 Anm. 107

- 17,357-384: 262, 238 Anm. 126

-17,352: 63 Anm. 69

- 17,385-397: 3 Anm. 9

- 18-19: 237

$-18: 121$

- 18,27: 83 Anm. 55

- 18,57: 149 Anm. 156

- 18,62-92: 178 Anm. 109

- 18,75-77: 78 Anm. 44

$-18,84: 31$

- 18,100-153: 175

- 18,107: 149 Anm. 157

-18,112: 69 Anm. 13

- 18,125: 63 Anm. 69

- 18,188: 63 Anm. 69

- 18,140: 149 Anm. 157

- 18,144: 68 Anm. 8

- 19,8f.: 63 Anm. 69

- 19,23-41: 175

- 19,51: 63 Anm. 69

- 19,56: 63 Anm. 69

- 19,59-348: 101

- 19,59-117: 121

- 19,73: 106 Anm. 29

-19,93: 63 Anm. 69

- 19,102-105: 101

$-19,104 \mathrm{f} .: 78 \mathrm{f}$. 
- 19,111: 149 Anm. 156

- 19,130 f.: 233 Anm. 107

- 19,130: 63 Anm. 69

- 19,169-197: 145 Anm. 137

- 19,178: 93 Anm. 95

- 19,180-188: 93 Anm. 95

- 19,181f.: 93 Anm. 95

- 19,182-184: 93 Anm. 95

- 19,184-186: 93 Anm. 95

- 19,187f.: 78 Anm. 44

- 19,203: 68 Anm. 8

- 19,214-218: 24 Anm. 17, 85

- 19,220: 149 Anm. 156

- 19,262: 233 Anm. 107

- 19,263-295: 29 Anm. 35

- 19,278: 29 Anm. 35

- 19,286: 29 Anm. 35

- 19,288: 29 Anm. 35

- 19,293: 29 Anm. 35

- 19,295: 29 Anm. 35

- 20: 33

- 20,1: 119

- 20,3: 221

- 20,4: 149 Anm. 157

- 20,10: 28 Anm. 31

- 20,11: 63 Anm. 69

- 20,103: 67 Anm. 6

- 20,157-165: 83 Anm. 55

- 20,190: 185 Anm. 134

$-20,207 \mathrm{f} .: 255$

- 20,296: 63 Anm. 69, 233 Anm. 107

- 20,300: 149 Anm. 157

- 20,308: 63 Anm. 69

$-21: 147$

$-21,1-62: 238$

$-21,28-32: 238$

- 21,29: 63 Anm. 69

- 21,36-52: 238

- 21,39: 63 Anm. 69

- 21,53: 63 Anm. 69

- 21,77: 63 Anm. 69

- 21,140: 63 Anm. 69

- 21,148ff.: 238 Anm. 126

- 21,153f.: 238

- 21,229: 69 Anm. 13

- 21,245: 149 Anm. 156

- 21,284: 69 Anm. 13

- 21,287: 63 Anm. 69

- 21,295-298: 238

- 21,298: 63 Anm. 69
- 22,42: 32 Anm. 44

- 22,90: 63 Anm. 69, 260

- 22,148: 22 Anm. 10

- 22,276-283: 145 Anm. 137

- 22,278f.: 255 Anm. 79

- 22,317: 149 Anm. 157

$-23-24: 33$

- 23,118: 32 Anm. 44

- 23,196-205: 115 Anm. 49

- 23,284-319: 146 Anm. 137

- 23,301: 32 Anm. 44

- 24,88-91: 234

- 24,32f.: 63 Anm. 69

- 24,44: 33 Anm. 54

- 24,136: 74 Anm. 26

- 24,242 - 260: 177 Anm. 102

- 25-40: 99

- 25,1-25: 70

$-25,1-10: 33$

$-25,8: 99$

$-25,20 \mathrm{f.:} 70$

- 25,21: 99 Anm. 15

- 25,198: 28 Anm. 30

- 25,265: 99

- 25,269: 99

- 25,297: 63 Anm. 69

- 25,326: 63 Anm. 69

- 25,332: 22 Anm. 10

- 25,364: 220 Anm. 64

- 25,380-572: 177, 209 Anm. 25

$-25,413-428: 85$

- 25,429-450: 84, 87 Anm. 66, 240 Anm. 129

$-25,451-552: 239$

$-25,451: 85$

$-25,529-538: 239$

$-25,539-552: 239$

- 25,541: 240

- 25,542: 240

$-25,545: 240,263$

- 25,549: 240

- 26: 178 Anm. 109

- 26,101-145: 239 Anm. 126

- 26,191: 260

- 26,213: 68 Anm. 9

- 26,268-290: 238f. Anm. 126

- 26,295 - 330: 135 Anm. 103

- 27,175: 149 Anm. 157

- 27,180f.: 63 Anm. 69

- 27,206: 63 Anm. 69

- 27,244-249: 85 
$-27,253: 56$

$-27,254: 56$

$-27,255 f .: 56$

$-27,255: 57$

- 28,128: 149 Anm. 157

- 28,164-167: 94

- 28,168-171: 94

- 28,263: 69 Anm. 13

- 28,289: 149 Anm. 156

- 28,330: 220 Anm. 64

- 28,327: 149 Anm. 156

- 29: 121

- 29,15-178: 51 Anm. 45, 235

- 29,15-48: 235

$-29,15-21: 235$

$-29,15: 236$

$-29,17: 236$

$-29,18 \mathrm{f.:} 236$

$-29,20 f .: 236$

$-29,22-48: 235$

$-29,32 \mathrm{f} .: 236$

$-29,49-86: 235$

- 29,87-150: 235

- 29,95-99: 78 Anm. 44, 79, 236

$-29,108-150: 56$

- 29,108-134: 235

- 29,108: 56, 57, 236

- 29,109-117: 236

$-29,118 \mathrm{f} .: 236$

- 29,120-126: 236

$-29,127-134: 236$

- 29,135-138: 236

- 29,142f.: 79 Anm. 45, 236

- 29,142: 78 Anm. 44

- 29,146-150: 237

- 29,151-166: 57

- 29,151-163: 235

- 29,151-162: 235

$-29,152: 236$

$-29,153: 57$

- 29,155: 57

$-29,156: 57$

- 29,162-178: 235

- 29,229: 233 Anm. 104

- 29,231: 63 Anm. 69

- 29,260: 233 Anm. 104

- 29,264-275: 239 Anm. 126

- 29,267: 63 Anm. 69

- 29,302: 63 Anm. 69

- 30,105-434: 94
- 30,127-186: 239 Anm. 126

- 30,199: 63 Anm. 69

- 30,259: 63 Anm. 69

- 31,3: 68 Anm. 8

- 31,229-282: 58

- 31,238f.: 58

- 31,239: 57 Anm. 65

- 31,242: 63 Anm. 69

- 31,243-250: 175

- 31,252-258: 85

- 32,27: 78 Anm. 44

- 32,91f.: 82

- 32,184: 99

- 33,21-59: 148 Anm. 151

- 33,75: 69 Anm. 13

- 33,64-104: 85

- 33,87: 149 Anm. 157

- 33,131-133: 78 Anm. 44

- 33,258: 22 Anm. 10

- 33,292-296: 83 Anm. 55

- 34,69-73: 239 Anm. 126

- 34,89-99: 136 Anm. 109

- 34,103-121: 145 Anm. 137

- 34,106-121: 51 Anm. 45

- 34,106-113: 136 Anm. 108

- 34,107: 220 Anm. 64

- 34,110: 220 Anm. 64

- 34,231-248: 115 Anm. 49

- 35,119: 196 Anm. 155

- 35,120: 33 Anm. 54

- 35,185-191: 26 Anm. 21

- 35,188: 33 Anm. 54

- 35,239: 67 Anm. 4

- 35,339: 63 Anm. 69

- 35,353-366: 238 Anm. 123

- 35,359: 233 Anm. 107

- 35,360: 63 Anm. 69

- 36,156: 63 Anm. 69

- 36,307-312: 55

- 36,325: 32 Anm. 44

- 36,356: 57 Anm. 65

- 36,356: 58

- 36,374: 63 Anm. 69

- 36,384: 233

- 37: 33, 101

- 37,103-778: 101

- 37,103: 63 Anm. 69

- 37,115: 22 Anm. 10

- 37,129: 22 Anm. 10

- 37,308: 83 Anm. 55 
- 37,314: 63 Anm. 69

- 37,122: 67 Anm. 7

- 37,137: 83 Anm. 55

- 37,320 - 323: 145 Anm. 137

- 37,338-341: 83 Anm. 55

- 37,546-613: 108

- 37,546-552: 108

$-37,548 f .: 108$

- 37,550: 108

- 37,553-557: 108

- 37,557-601: 108

- 37,602-609: 108

- 37,610-613: 108

- 37,614-666: 111

- 37,614-618: 111

$-37,616-618: 112$

- 37,619-659: 111

- 37,622-630: 111

- 37,630-633: 112

- 37,631: 112

- 37,639-643: 112

- 37,640-645: 113 Anm. 45

- 37,644-656: 112

- 37,660-663: 111

- 37,664-666: 112

- 37,664: 112

- 37,722-749: 235

- 37,729: 32 Anm. 44

$-38,1: 119$

- 38,25: 220 Anm. 64

- 38,85: 73

- 38,105-434: 147 Anm. 148

- 38,116-129: 26 Anm. 21

- 38,131: 220 Anm. 64

- 38,157: 32 Anm. 44

- 38,195: 32 Anm. 44

- 38,247: 69 Anm. 13

- 38,290: 220 Anm. 64

- 38,298: 220 Anm. 64

- 38,331: 220 Anm. 64

- 38,400-405: 95

- 38,406: 32 Anm. 44

- 38,415: 220 Anm. 64

- 39-40: 33

- 39,57: 233 Anm. 107

- 39,62-73: 85

- 39,64-66: 87 Anm. 65

- 39,72f.: 57 Anm. 65, 58

- 39,174-211: 112 Anm. 43

- 39,356-360: 239 Anm. 126
- 40,91: 63 Anm. 69

- 40,256 f.: 78 Anm. 44

- 40,298-365: 178, 135

- 40,305-310: 135 Anm. 103

- 40,338-352: 145 f. Anm. 137

- 40,369 - 410: 145 Anm. 137

- 40,396 f.: 239 Anm. 126

- 41-48: 156

- 41,6: 63 Anm. 69

- 41,9: 233

- 41,13: 63 Anm. 69

- 41,14-50: 178

- 41,78: 149 Anm. 157

- 41,86: 22 Anm. 10

- 41,143-154: 145 Anm. 137

- 41,155-262: 26 Anm. 21

- 41,155-157: 220

-41,184: 220 Anm. 64

- 41,191: 32 Anm. 44

- 41,225-227: 26 Anm. 21

- 41,228f.: 194

- 41,234: 149 Anm. 157

- 41,250-262: 51 Anm. 45

- 41,273-398: 220

- 41,338-398: 192 Anm. 147

- 41,338-360: 177

- 41,350: 32 Anm. 44

- 41,421: 63 Anm. 69

-42,40: 63 Anm. 69

- 42,181: 99

$-42,303-312: 79$

- 42,205-273: 122 Anm. 66

- 42,294-300: 78 Anm. 44, 79, 82

- 42,296: 57 Anm. 65, 58

- 42,302: 79

- 42,304: 260

- 42,333-335: 136 Anm. 109

- 42,402: 63 Anm. 69

- 42,278: 63 Anm. 69

- 42,522: 63 Anm. 69

- 43,24: 57 Anm. 65, 58

- 43,25f.: 68 Anm. 8

- 43,25: 234 Anm. 107

- 43,52-68: 237

- 43,67: 234 Anm. 108

- 43,68: 63 Anm. 69

- 43,85: 63 Anm. 69

- 43,126f.: 57 Anm. 65, 58

- 43,171: 63 Anm. 69

- 43,285: 69 Anm. 13 
- 43,295: 71 Anm. 20

- 43,310: 149 Anm. 157

- 43,322: 63 Anm. 69

- 43,345: 149 Anm. 157

- 43,346: 71 Anm. 20

- 43,348: 74 Anm. 26

- 43,377: 63 Anm. 69

- 43,411: 22 Anm. 10

- 43,442: 22 Anm. 10

- 44-46: 147

- 44,30: 74 Anm. 26

- 44,84-106: 230 Anm. 99

- 44,154: 63 Anm. 69

- 44,191-216: 145 Anm. 137

- 44,218-252: 146 Anm. 137

- 44,218: 260

- 44,241: 63 Anm. 69

- 45,14: 63 Anm. 69

- 45,82-94: 175

-45,137-151: 238 Anm. 124

$-45,143: 233$

- 45,146: 63 Anm. 69

- 45,196: 196 Anm. 155

- 45,275: 149 Anm. 157

- 45,278: 149 Anm. 156

- 45,312: 233

- 45,344: 149 Anm. 157

- 46,7: 28 Anm. 31

- 46,8f.: 68 Anm. 8

- 46,10-51: 175

- 46,27: 176

- 46,41: 176

- 46,70: 63 Anm. 69

- 46,141: 68 Anm. 8

- 46,144: 63 Anm. 69

- 46,148: 63 Anm. 69

- 46,187: 149 Anm. 157

- 47,34-264: 135 Anm. 105, 237

- 47,20: 221

-47,27: 22 Anm. 10

- 47,52 f.: 85

- 47,66: 260

- 47,71: 63 Anm. 69

- 47,76-78: 87 Anm. 65

- 47,90: 221

- 47,97f.: 85, 87 Anm. 65

- 47,226: 149 Anm. 157

- 47,246-264: 237

- 47,328 -349: 136 Anm. 109

- 47,502: 32 Anm. 44
- 47,525: 63 Anm. 69

- 47,599: 22 Anm. 10

-47,658: 67 Anm. 4

- 48: 108

- 48,57: 32 Anm. 44

- 48,106-182: 101

$-48,106$ f.: 108

- 48,108: 109

- 48,112: 109

- 48,116-123: 51 Anm. 45

- 48,125: 109

- 48,161-163: 108

- 48,174: 109

- 48,178f.: 109

- 48,212-214: 83 Anm. 55

- 48,251: 74 Anm. 26

- 48,302-375: 26 Anm. 21

- 48,535: 74 Anm. 26

- 48,571-589: 79

$-48,577$ f.: 221

- 48,581-589: 78 Anm. 44

- 48,581-586: 80

- 48,587: 79

- 48,646: 63 Anm. 69

- 48,801: 220 Anm. 64

- 48,974: 63 Anm. 69

- 48,976f.: 87 Anm. 65

P. 1,39: 28 Anm. 30

- 1,132: 32 Anm. 44

- 1,191: 226 Anm. 91

- 2: 38, 262

- 2,37: 196 Anm. 155

- 3,79: 226 Anm. 91

$-4,13: 262$

$-4,13-19: 261$

$-4,15: 262$

- 4,16: 63 Anm. 69, 262

- 4,97-103: 230 Anm. 99

- 4,205: 226 Anm. 91

- 5,8: 33 Anm. 54

- 5,23: 32 Anm. 45

- 5,82: 262

- 5,154: 187 Anm. 139

- 6: 69 Anm. 13

- 6,1-52: 23 Anm. 13

- 6,7: 69 Anm. 13

- 6,147: 226 Anm. 91

$-6,162: 263$

- 6,179: 226 Anm. 91

- 7,160: 187 Anm. 139 
- 8,94: 226 Anm. 91

- 8,157: 226 Anm. 91

- 9,3: 226 Anm. 91

- 9,9: 226 Anm. 91

- 9,84: 149 Anm. 157

- 9,154: 226 Anm. 91

- 9,174: 67 Anm. 6

- 10,61: 263

- 10,102: 226 Anm. 91

-11,1-185: 262

- 11,16: 226 Anm. 91

-11,112: 24 Anm. 15

- 11,123 f.: 16

- 11,33: 226 Anm. 91

-11,47: 262

- 11,87: 226 Anm. 91

- 11,164: 262

- 12,198: 226 Anm. 91

-13,1-16: 250 Anm. 54

- 13,38: 226 Anm. 91

-13,66: 33 Anm. 54

- 15,1-19: 16

-15,2: 57 Anm. 65

-15,3: 63 Anm. 71

- 15,11: 63 Anm. 69

- 15,15: 57 Anm. 65, 76 Anm. 32

- 15,21: 63 Anm. 69

- 15,25f.: 63 Anm. 69

$-18,8: 260$

- 18,22-24: 69 Anm. 13

- 18,22: 69 Anm. 13

- 18,24: 69 Anm. 13

- 18,65: 210 Anm. 30

- 20,32: 32 Anm. 45

$-20,67: 260$

- 20,119 f.: 67 Anm. 4

- 21,31: 24 Anm. 15

Opp.

-C. 1,365: 234 Anm. 108

$-2,85: 215$

- 2,289: 24 Anm. 15

- 3,255: 67 Anm. 7

- 3,478: 214 Anm. 43

- 3,497: 32 Anm. 44

- H. 1,622: 185

-1,763: 28 Anm. 30

- 2,604: 24 Anm. 15

Orph.

- A. 5: 69 Anm. 9

- 594: 119 Anm. 52
- Fr. 214 Kern: 40

- H. 54,6: 234 Anm. 108

- 77,2: 69 Anm. 9

Ov.

- fast. 3,403-414: 42, 89

- 3,413: 42

- 4,329-333: 51

- met. 2,25-30: 250

- 2,27-30: 180 f. Anm. 121

- 4,321: 67 Anm. 4

- 10,123-125: 81 Anm. 49

- 10,162-219: 74

- 11,44-49: 132 Anm. 82

- 15,211: 184 Anm. 131

Paul. Sil.

- Soph. 821: 32 Anm. 44

Paus.

- 2,35,1: 115 Anm. 47

- 3,19,3: 74 Anm. 27

- 3,19,5: 75 Anm. 30

-6,20,19: 94 Anm. 98

- 10,38,1: 40 Anm. 3

Peripl. M. Rubr.

- 42,7: 69 Anm. 13

Philostr.

- Im. 1,24: 74 Anm. 27

$-1,26: 224$

$-2,34,2: 224$

Pi.

- Fr. 52d,25 f.: 71 Anm. 19

-70a-88: 70

-70b: 70

- 108b,3f.: 185 Anm. 134

- 124a: 149 Anm. 157

- 124,2 - 6: 71 Anm. 19

- 157: 56 Anm. 62

- 248: 71 Anm. 19

- I. 1,7: 68 Anm. 8

- 4,18: 71 Anm. 19

$-4,23 \mathrm{f.:} 72$

- N. 1,16: 71 Anm. 19

- 8,2: 71 Anm. 19

- 9: 70

- 10,75-85: 71 Anm. 19

- $0.1,25: 83$

$-1,36-45: 84,88$

$-1,41: 83$

$-1,42: 83$

$-1,69: 83$

$-1,70: 83$ 
$-1,80: 83$

$-1,87: 83$

$-2: 70$

- 2,27: 234 Anm. 108

- 7,2: 71 Anm. 19

- 7,71: 71 Anm. 19

- 7,95: 185 Anm. 134

- 10,84: 149

- 10,93: 71 Anm. 19

- 13,17: 71 Anm. 19

- P. 2,10: 71 Anm. 19

-3,14: 68 Anm. 8

- 4,79-100: 71

$-4,81: 71$

$-4,82$ f.: 51,71

$-4,83: 71$

$-4,86-100: 71$

$-5,11: 71$

- 5,120: 71 Anm. 19

- 8,95: 56 Anm. 62

- 9,59-61: 224

- 9,109 f.: 71 Anm. 19

-11: 70

- 12,24: 71 Anm. 19

- Pae. 4 (= Pi. Fr. 52d): 70

Pl.

- Lg. 3,689d: 115

- Phdr. 255b-c: 88 Anm. 74

Plot.

- Ennead. 1,6,8: 82 Anm. 54

POxy.

$-3723=$ SSH 1186: 88

Procop. Gaz.

-Op. I (= Dial. 1): 165, 256 Anm. 84

- Op. I (= Dial. 1),2: 77 Anm. 39

- Op. II (= Dial. 2): 165, 256 Anm. 84

-Op. III (= Dial. 3): 165

- Op. IV (= Ethop. 1): 165

-Op. V (=Ethop. 2): 165

- Op. VI (= Ethop. 3): 165

- Op. VIII (= Descr. 1): 177 Anm. 96

- Op. IX (= Descr. 2): 177 Anm. 96

Prud.

- perist. 13,28 - 32: 51 Anm. 49

Q. S.

- 1,37-40: 69 Anm. 13

- 1,48-51: 187 Anm. 140

- 1,147-149: 69 Anm. 13

$-1,293: 185$

- 2,531: 52 Anm. 52
- 2,557: 52 Anm. 52

- 2,593-595: 187 Anm. 140

- 4,159: 52 Anm. 52

- 4,180 - 595: 102 Anm. 24

$-5,37: 52$ Anm. 52

- 8,203: 52 Anm. 52

- 8,313: 52 Anm. 52

- 8,427-442: 88 Anm. 68

-14,175-178: 234 Anm. 107

- 14,207f.: 223 Anm. 73

-14,325f.: 88 Anm. 68

S.

- El. 680-763: 141, 148

- OC 668-719: 82

- 674f.: 82 Anm. 53

- 678-680: 82 Anm. 53

- 681-685: 82 Anm. 53

- OT 473-475: 185

- 478: 186

Sapph.

- fr. 96,6-9 Lobel u. Page: 51

Septuaginta siehe $L X X$

Serv.

- in ecl. 5,48: 212

Sidon.

- epist. (carm. 22) 6: 248

- carm. 7,1-16: 245

$-7,17-44: 245$

$-7,45-122: 245$

$-7,123-138: 245$

$-7,153-602: 245$

$-7,139-152: 245$

$-15,200: 250$

Simon.

- fr. 146 Bergk = AP 13,28: 224

Stat.

- silv. 3,4: 159 Anm. 45

Str.

- 9,2,24: 94 Anm. 98

-13,1,23: 22 Anm. 9

- 13,3,5: 22 Anm. 9

Suid.

- $\mu$ 989: 115 Anm. 48

- $\varphi$ 877: 260 Anm. 105

Synes.

- hymn. 1,700: 67 Anm. 5

Them.

- Or. 20: 158 Anm. 45

Theoc.

$-1,66-142: 132$ 
- 1,132-136: 81

- 2,55: 133 Anm. 85

$-2,79: 51$

- 4,40: 133 Anm. 85

$-6,12: 33$

- 7,121: 133 Anm. 85

-10,28: 77 Anm. 38

-11,26: 77 Anm. 38

-12,7: 69 Anm. 9

- 13: 90

- 13,7: 90 Anm. 82

$-13,36-39: 92$

- 13,53f.: 90 Anm. 82

- 13,58-60: 92 Anm. 91

- 13,61-64: 91 Anm. 86

- 13,66f.: 91

- 13,72: 92

$-15,124-142: 88$

\section{Register griechischer Wörter}

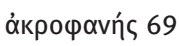

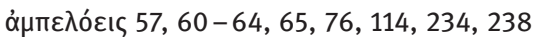

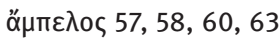

$\alpha u ̛ \delta \eta ́ \varepsilon v \tau \alpha 76$

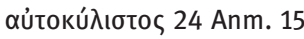

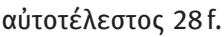

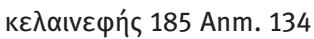

кıббофо́роৎ 234

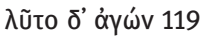

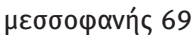

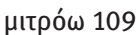

$-15,128: 215$

$-18,2: 77$

- 20,13: 74 Anm. 26

Theon

- Prog. 9,1: 158 Anm. 44

- 118,1,7: 178 Anm. 105

Verg.

- Aen. 1,28: 85

- 5,104-544: 102 Anm. 24

- 6,453f.: 69 Anm. 13

- 7,488: 81 Anm. 49

- georg. 3,267f.: 94 Anm. 98

X. Eph.

- 1,8: 135 Anm. 100

- 1,14,4-6: 140 Anm. 124

$-3,2: 140$

$-3,2,11 \mathrm{f} .: 140$

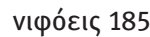

vóӨos 193

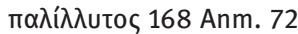

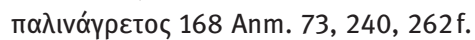

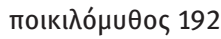

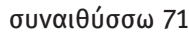

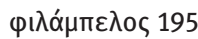

фıлєúıৎ 61, 195

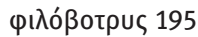

фчтпко́но 207, 260 